\title{
JUSTIFICATION OF RADIOLOGICAL PROCEDURES ALGORITHM ADJUSTMENT IN DIAGNOSIS OF LOWER BACK PAIN CAUSE AT UNIVERSITY CLINICAL CENTER TUZLA
}

Aida Denjagić, Munevera Bećarević, Haris Huseinagić, Nihad Mešanović

(C) by Acta Medica Saliniana ISSN 0350-364X

Type of manuscript: Professional papers

\section{Title:}

JUSTIFICATION OF RADIOLOGICAL PROCEDURES ALGORITHM ADJUSTMENT IN DIAGNOSIS OF LOWER BACK PAIN CAUSE AT UNIVERSITY CLINICAL CENTER TUZLA

Authors:

Aida Denjagić ${ }^{1}$

Munevera Bećarević

Haris Huseinagić ${ }^{1,2}$

Nihad Mešanović ${ }^{2}$

DOI: $10.5457 / 489$

\section{Afiliations:}

${ }^{1}$ Faculty of Medicine, Department of

Health Studies, University of Tuzla

${ }^{2}$ The University Clinical Center Tuzla

Received:

11.01.2019.

Corresponding author:

Aida Denjagić,

Faculty of Medicine, Department

of Health Studies, University of

Tuzla, Bosnia and Herzegovina,

Univerzitetska 1, 75000 Tuzla,

Bosnia and Herzegovina

Phone:+38761253946

E-mail: denjagic.aida@hotmail.com

Introduction: Lower Back Pain (LBP) is one of the most frequent reasons for visiting physican. Authors of guidelines scrutinizing use of radiography and Computed tomography (CT) or Magnetic resonance imaging (MRI) in LBP diagnostic. Method of choice in the LBP diagnostic should be MRI except in cases where we should get diagnostic informations as soon as possible (traumas etc.) and in strict indications in bone structures where CT should be a method of choice. Increase of $\mathrm{CT}$ use and following icrease $\mathrm{CT}$ derived radiation dose in patients are very serious problems of last decades. Aim: To show the nessesary of procedure algorithm adjusment in LBP diagnostic. Reasons are: danger of overdiagnosis leading to chronifications, loosing time and money to get exact diagnose and leading to cumulate very high ionizing doses $(10 \mathrm{mSv}$ per person with average body weight from lumbar spine CT) that could couse a cancer if it is over $100 \mathrm{mSv}$ (in some studies if it is over $50 \mathrm{mSv}$ ). Patients and methods: Sixty-nine patients, average age of 51.35 years, were included in the study. Lumbar spine CT was performed and repeated procedure at MRI in a very short time in Clinic for Radiology and Nuclear Medicine of University Clinical Centre Tuzla from January 12017 to February 9 2018. The sample of patients was formed consecutively. Referral diagnosis for CT procedures were: M51 in 36 patients (52.17\%), N/A in $13(18.84 \%)$, M05 in 4 (5.8\%), G83.4 in 3 (4.35\%) and other in 13 (18.84\%). Results: 30 $(83.33 \%)$ of patients were referred from CT to MRI procedure in time under 42 days (during acute phase). Relation of justified and unjustified undertaken CT procedures were: $71 \%$ unjustified, 10\% justified and 19\% N/A. Conclusion: Performed study showed unjustified undertaken $\mathrm{CT}$ procedures and high unnecessary radiation dose in $71 \%$ patients. There are justified reasons for procedure algorithm adjusment in LBP diagnostic.

Key words: lower back pain, diagnostic procedure algorithm, CT, MRI.

\section{INTRODUCTION}

In the order of execution during usual medical practice, radiological methods are classified to the third place, after physical examination and laboratory diagnostic procedures.

Considering the reason for radiological imaging performing, prevention includes not only protection of ionizing radiation exposure, but also a proper choice of modality, or modality algorithm if by one of them is not possible to obtain reliable diagnostic results.

Lower Back Pain (LBP) is defined as the apperiance of pain along the lumbar or sacral spine region with or without pain spreading towards the lower extremities (reticular pain) (Casser at al., 2016).

About $70 \%$ of adults have at least an episode of LBP per year (Casser at al., 2016). A retrospective study of Hart (Hart at al., 1995), that covered a 5 -year period in United States of America (USA), ranked LBP as a fifth reason for visiting to a physican (Hart at al., 1995). The causes of LBP are numerous, but the primary source of the pain is caused by disorders related to the spine (mechanical, degenerative, inborn, traumatic) and could also be associated with abdominal and pelvic diseases.

An acute LBP is considered a pain lasting up to 6 weeks, subacut from 6 to 12 weeks and chronic over 12 weeks. Treatment of acute pain, except possible plain x-ray performing, usually does not imply the urgency of a further radiological imaging because $80 \%$ of acute pain have been resolved by analgesics or additional physical theraphy. If the pain persists for more than 6 weeks, the goal is to diagnose the cause of pain before reaching to a chronic phase, which is at the beginning manifested by the increased pain intensity, reduced ability and leads to a function restriction (Linder at al., 2016; Andersen, 2011).

The authors of the guidelines and health insurance beneficiaries critically scrutinizing use of conventional radiography; Computed Tomography (CT); Magnetic Resonance Imaging (MRI) and their algorithm (Carey \& Garret, 1996). 
In the decision on the choice of radiological diagnostic modality in urgent situations, it's indisputable the most important is to get informations as soon as possible, so clearly the method of choice is CT. This study does not concern urgent situations. It deals with the justification of additional radiological examinations that do not require urgent treatment and there are suspicions of the soft tissue damage. If these patients, after the initial plain x-ray performing, should be referred to the CT, it is possible that we will not get a proper view of the patology (Figure 1, Figure 2). These changes are much better visualized by MRI. Performing CT in that situations are unnecessary diagnostic procedure that provides much more harm then it benefits. Such patient will be mostly additionaly referred to MRI. Effective exposure dose per patient of average body weight by lumbar CT performing is $10 \mathrm{mSv}$ which is almost the ten-fold dose recived by lumbar plain x-ray. MRI is a method that does not use ionizing radiation during the performing.

During the application of ionizing radiation there is a principle that states as follow: doses of radiation should be at the lowest possible level, without reducing the required quality of the information obtained by performing (As Low As Reasonably Achiveable, ALARA) (Hebrang at al., 2007). ALARA principle is directly derived from the Latin principle "Primum non nocere".

Knowing the harmful effects of radiation, the purpose of the principle should be clear- before performing any of imaging procedure, it should be weight value of the diagnostic benefit, as a necessary expected search results, and possible harmful consequences of the search- Risk to Benefit Ratio (RBR). So, any exposure to radiation is associated with certan dangers which could be nevertheless acceptable in relation to the expected benefits in treatment.

Radiological imaging is justified only if it could contribute to the definition of the disease, choosing proper treatment, reducing the risk of possible complications or reducing patient's pain. Also, it is not justified if it only confirms the already existing diagnoses which will not significantly affect the decision of the type of treatment.

Today, when cosequences of radiation exposure are known, the most important issue is the fact that is not consider enough about the long-term latency as a harmful consequence. Delayed apparence of consequences after radiation exposure in the following period would prevent linking of causes and consequences. It does not particularly pay attention to the cumulative dose of radiation that patient would be exposed during repetedly exposures in a short period of time (Bohl at al., 2017). The possibility of a radiationinduced carcinogenesis if it is over $50 \mathrm{mSv}$ for children and over $100 \mathrm{mSv}$ for adults.

The basis of prevention is the existence of a properly medical indications for the radiological exposures. Whenever possible it would be selected for radiological imaging which exludes the use of ionizing radiationUltra Sound (US) or MRI.

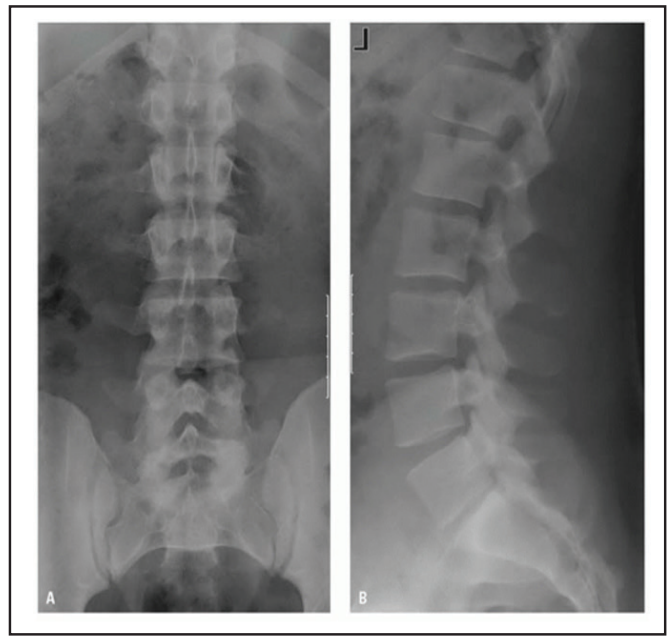

Figure 1. Lumbar spine plain film in two projections: left-A/P;right-L//L (Konin, 2010)

\section{Hypothesis}

\section{Alternative Hypothesis:}

1. Patients with lower back pain, after the lumbar computed tomography scanning, for a large percentage are sent to additional repeted lumbar magnetic resonance imaging;

2. There are adventages of diagnosting lower back pain by magnetic resonance imaging in relation to computed tomography;

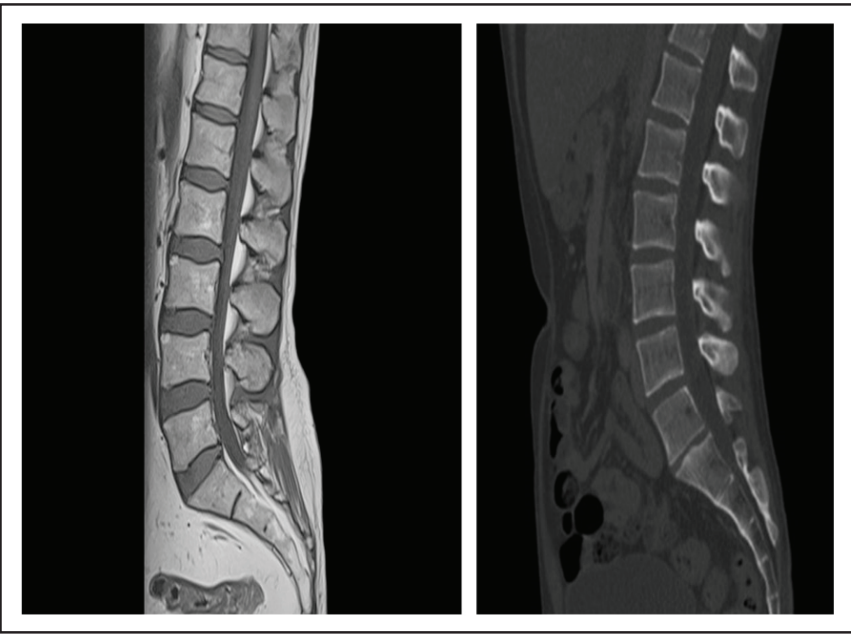

Figure 2. Comparative lumbar spine scans: left-MRI; right- CT (Zeller, 2006)

3. It is possible to present justified reasons for adjustening the algorithm of the aforementioned imaging procedures at the University Clinical Center (UCC) Tuzla.

\section{Null Hypothesis:}

1. Patients with lower back pain, after the lumbar computed tomography scanning, for a large percentage are not been sent to additional repeted lumbar magnetic resonance imaging; 
2. There are not adventages of diagnosting lower back pain by magnetic resonance imaging in relation to computed tomography;

3. It is not possible to present justified reasons for adjustening the algorithm of the aforementioned imaging procedures at the University Clinical Center Tuzla.

\section{Aims of the study:}

1. To determine the necessity of radiological procedures adjustment in diagnostics of lower back pain and to present the justification of it;

2. To recommend the adjusting of the existing algorithm in lower back pain diagnostics in order to protect the patients from unnecessary radiation;

3. To point the possibility of shortening the procedure in lower back pain diagnostics as well as financial savings due to potential algorithm adjustment.

\section{METHODS}

\section{Search procedures}

This study had a retrospective character. It is taken at the Clinic for radiology and nuclear medicine of University Clinic Center in the Tuzla. The sample of patients was formed consecutively. The study included 69 patients whom are in period Jan 1st 2017 to Feb 9th 2018 after the lumbar CT scanning sent to the same part of spine an additional repeted MR imaging.

\section{Study included criteria:}

- patients who, after the lumbar CT scanning, were sent at additionaly the same spinal segment by MR imaging;

- both mentioned procedures were performed at the Clinic for radiology and nuclear medicine in the Tuzla.

\section{Study exluded criteria:}

- any of abovementioned procedures were performed elsewhere from the Clinic for radiology and nuclear medicine in the Tuzla;

- pregnant women;

- claustrophobic patients;

- anxiety patients;

- patients with implanted pacemaker, metal implants or shell grenade peaces.

\section{Mehtods}

Methods used during data collection of the research are lumbar CT scanning and in a very short period of time additional lumbar MRI of the same patients which are both of procedures performed at the Clinic for radiology and nuclear medicine in the Tuzla.
Before the patients were reffered to CT performing, they also, in a large number, performed the lumbar plain $\mathrm{x}$-ray. If it considered the patients with higher body weight, the visualization by plain $\mathrm{x}$-ray was reduced. Conventonal radiography, which allows visualization of bone structures in two dimensions, provides data about two-dimensional visualization in two projections: anterio-posterior and latero-lateral $(\mathrm{A} / \mathrm{P}$ and $\mathrm{L} / \mathrm{L})$. Soft tissue damages were possibly visualized only if there were present at a higher intensity. The most likely reason for referring the additional procedures was the insufficiency of data obtained by conventional radiography. Following present algorithm, the first of additional procedure was $\mathrm{CT}$ which during the scanning involves rather large doses of ionizing radiation compared to conventional radiography. CT scanning visualized bone structure damages better compared to plain $\mathrm{x}$-ray, with possibly required visualization of soft tissue damages. CT performance obtained sagittal, two-dimensional visualization. The scans, as row data, are possible to get transversal, coronal and threedimensional reconstruction by postprocessing. Before of patients referring on this procedure, it was necessary to determine risks and benefits of its utilizing and based of that, made the right decision. MR imaging should be the method of choice during lubar diagnostics. The reason is that the largest percent of damage in that area refers to soft tissue damage and MRI provides the best visualization of it. MR imaginng is a diagnostic method that does not utilize ionizing radiation during the performance and it simultaneously provides data visualization in all three planes.

All the obtained data are stored in the computer digital system for archiving images and communication (Picture Archiving and Communication System, PACS). Written medical records are stored in Radiology Information System (RIS), in the form of Word documents (under the codes CT 47, CT 53, CT 54, MR 09 and MR 09A).

\section{RESULTS}

Sixty-nine of patients, average age of 51.35 years, were included in the study. In a group of male patients average age was 50.15 year, in a group of female 52.51. The youngest patient was 22 years old, the oldest one 76 .

The total number of patient distribution by gender and age groups are displayed in Table 1. Both genders were represented the most by age group 35-49 and 50-64.

By frequency of referral diagnosis on CT the most common was M51 ("other diseases of intervertebral disc") in 36 of patients (52.17\%). It was followed by a group with notavailable diagnosis (N/A) in 13 (18.84\%), then "seropositive rheumatoid arthritis" (M05) in 4 (5.8\%) and "syndrome of cauda equina" (G83.4) in 3 of patients (4.35\%). All others were recorded rarely and total of them were 13 (18.84\%) (Figure 3). 
Table 1. Total number of patient distribution by gender and age groups

\begin{tabular}{|c|c|c|c|c|c|}
\hline \multirow{2}{*}{$\begin{array}{c}\text { Age } \\
\text { Group }\end{array}$} & \multicolumn{2}{|c|}{ Total No. of patient } & \multicolumn{2}{c|}{ Total of Male } & $\begin{array}{c}\text { Total of } \\
\text { Female }\end{array}$ \\
\cline { 2 - 6 } & $\mathrm{N}$ & $\%$ & $\mathrm{~N}$ & $\%$ & $\mathrm{~N}$ \\
\hline $20-34$ & 7 & 10.14 & 5 & 7.24 & 2 \\
\hline $35-49$ & 18 & 26.09 & 8 & 11.60 & 10 \\
\hline $50-64$ & 37 & 53.63 & 17 & 24.64 & 20 \\
\hline $65-79$ & 7 & 10.14 & 4 & 5.79 & 3 \\
\hline Total & 69 & 100 & 34 & 49.28 & 35 \\
\hline
\end{tabular}

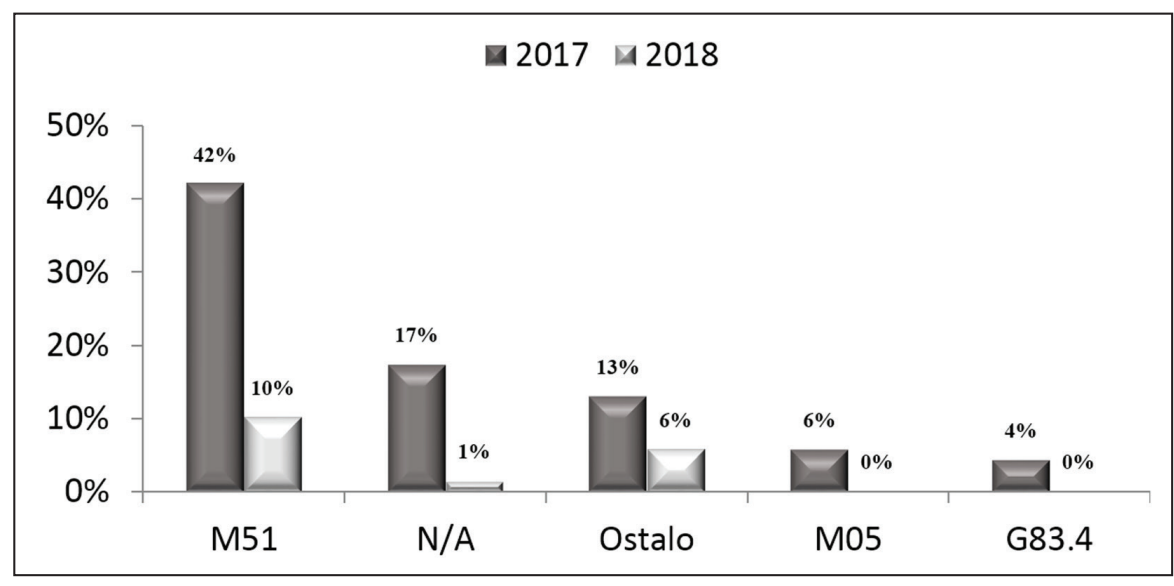

Figure 3. Referral diagnoses distribution to CT procedures by frequency

Table 2. Distribution of patients by reference diagnosis M51 to CT procedures by gender and age groups

\begin{tabular}{|c|c|c|c|c|c|}
\hline \multirow{2}{*}{$\begin{array}{c}\text { Age } \\
\text { Group }\end{array}$} & \multicolumn{2}{|c|}{ Total No. of patient } & \multicolumn{2}{c|}{ Total of Male } & $\begin{array}{c}\text { Total of } \\
\text { Female }\end{array}$ \\
\cline { 2 - 6 } & $\mathrm{N}$ & $\%$ & $\mathrm{~N}$ & $\%$ & $\mathrm{~N}$ \\
\hline $20-34$ & 3 & 8.33 & 3 & 16.67 & 0 \\
\hline $35-49$ & 10 & 27.78 & 3 & 16.67 & 7 \\
\hline $50-64$ & 19 & 52.78 & 10 & 55.55 & 9 \\
\hline $65-79$ & 4 & 11.11 & 2 & 11.11 & 2 \\
\hline Total & 36 & 100 & 18 & 100 & 18 \\
\hline
\end{tabular}

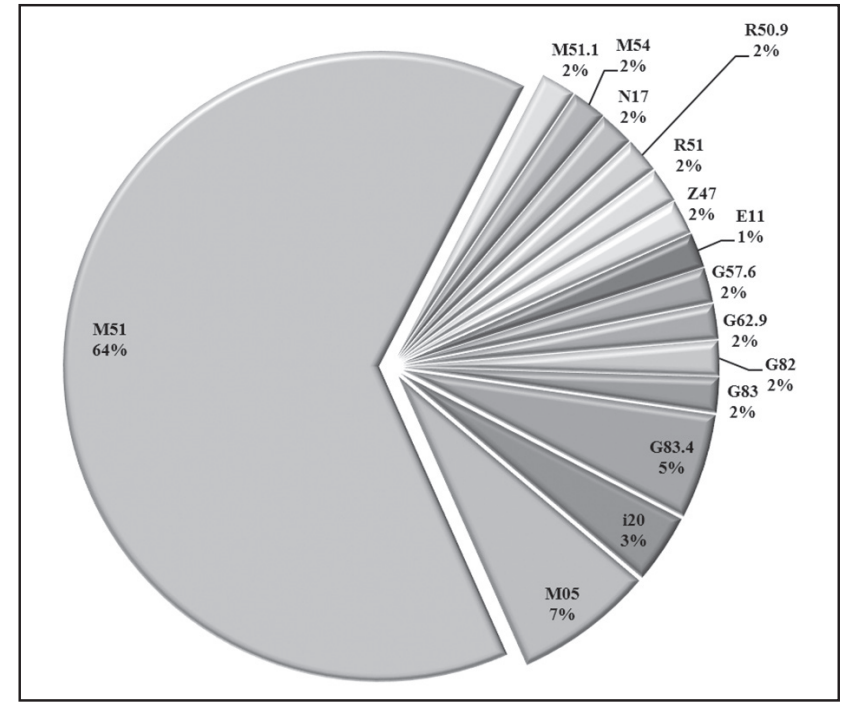

Figure 4. Avaliable referral diagnosis distribution to CT procedures by frequency 
Of 56 avaliable referral diagnosis on CT, the most frequent was M51=36 times (64.29\%), then M05=4 (7.14\%), G83.4=3 (5.36\%) and $\mathrm{I} 20=2$ (3.57\%). All other diagnosis were recorded only once each with each participation of $1.79 \%$ (Figure 4).

In total we had 69 referral diagnosis for CT scanning56 (81.16\%) available and 13 (18.84\%) anavaliable. By International Classification of Diseases (ICD) it was possible to get insight into referral diagnoses to
CT and MRI and their justification for CT performing. It was obviously that only 7 of diagnosis $(12.5 \%)$ had an indication for CT scanning because they do not point out on soft tissue pathology. For the rest of 49 $(87.5 \%)$ it was obvious that they were pointing out to the suspicion of soft tissue damage. This would be an indication for MR imaging, unless it was an urgent situation where we should get information as soon as possible. In that case CT should be the first performed diagnostic method.

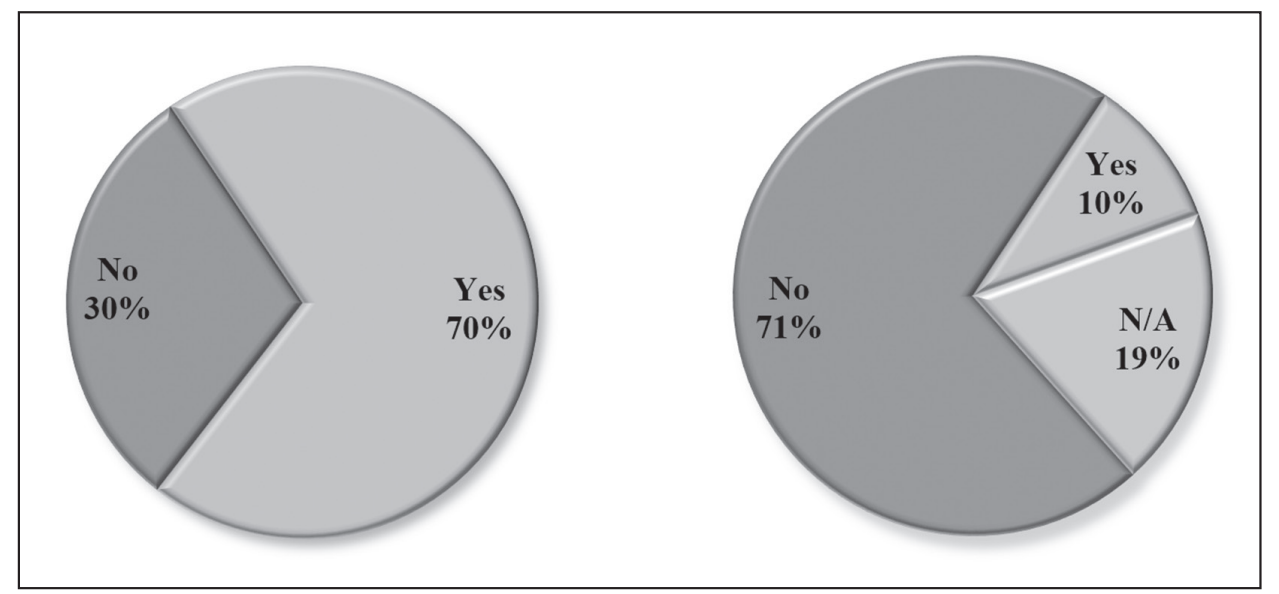

Figure 5. Justified and unjustified undertaken CT procedures relation with regard to referral diagnosis (left- world average results, Linder at al.,2016; right- results of the research, UCC Tuzla)

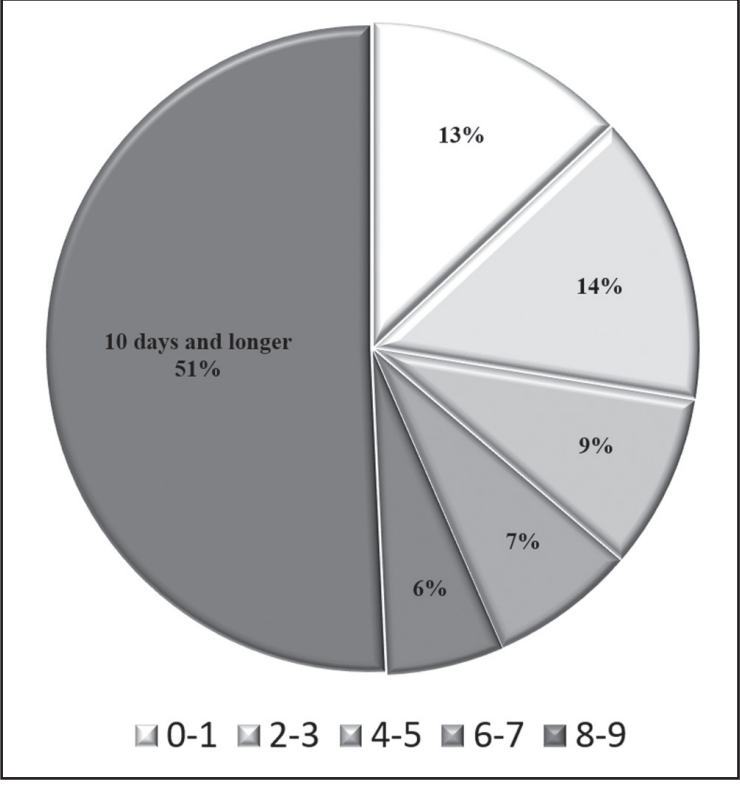

Figure 6. The number of patients compared to the total number of patients in whom CT and MR procedures were taken within 9 days

It's noticeable worring percent of unjustified CT performing, even 49 of 56 (83.93\%) which greatly deviates from the worlds average of $30 \%$. Even if we were considering those 49 unjustified undertaken CT performing on total of undertaken procedures (considering 13 of N/A as justified), again we should have worring percentage- $71.01 \%$ (Figure 5). The same number of 49 patients, which was $71.01 \%$ of the total number of patients, was necessarly recived an average dose of $10 \mathrm{mSv}$ during the CT scanning.
Results indicates the time passed from CT scanning to additional MR imaging were as follow: even 9 (13.04\%) of patients performed additional MRI the same day or the next day from the previous undertaken CT (Figure 6). Until third day from the undertaken CT to MRI the number of patients increased to 19 (27.54\%), that by the eight day reached the number of 34 patients (49.28\%). Even 57 (82.61\%) of patients performed additional MR imaging for the duration of the acute phase of LBP (within 42 days). 
By the stages of acuteness LBP is divided into three phases: acute- under 42 days, subacute-43-84 and chronic- over 85 days.

In this regard, the results were as follows: in a group within 42 days passed since CT to MRI, which could be considered an acute phase of pain, we had 57 of patients (82.61\%), in a group 43-84=2 (2.90\%) and in a group over 85 days we had 10 (14.49\%) (Figure 7). Within 9 days passed from CT scanning even $49.28 \%$ of patients were already done additional MRI.

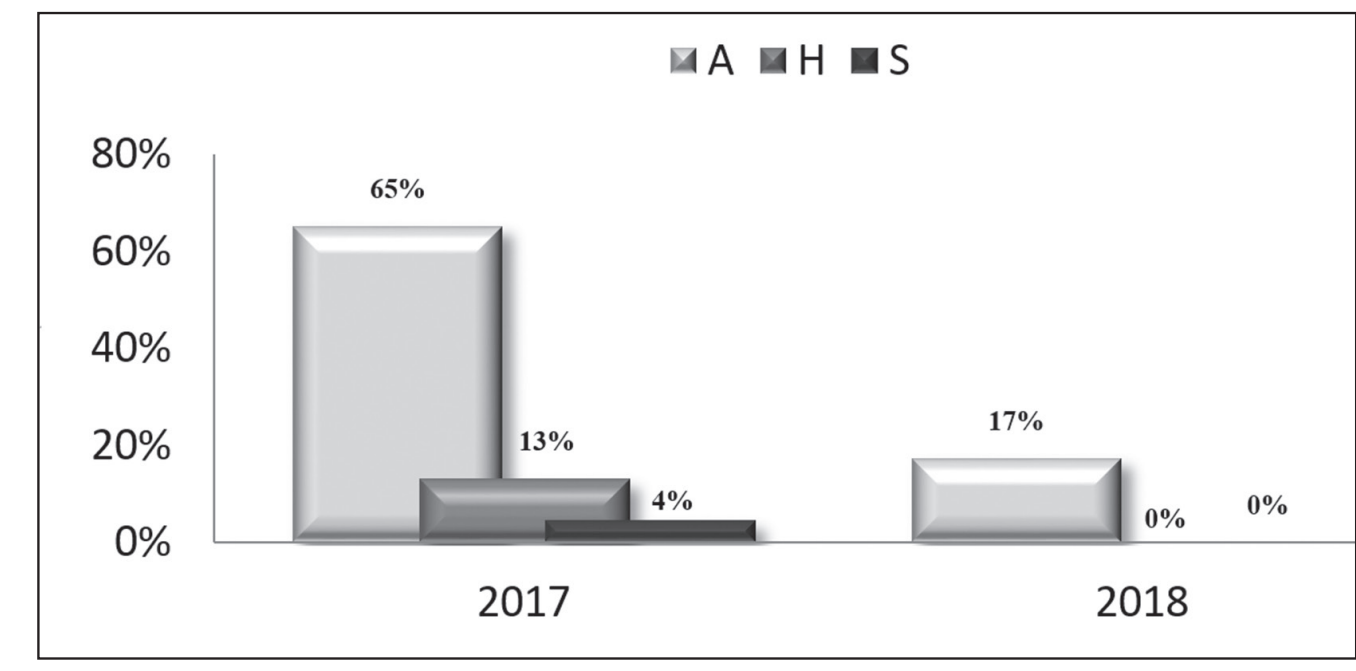

Figure 7. The total number of patients by days past since CT to MRI performing throught the different stages of pain

\section{DISCUTION}

Results of a referral diagnoses on CT point to a big failure. Even $52 \%$ of patients were sent under M51 diagnosis, "other diseases of the intervertebral disc". That diagnosis indicates an intervertebral disc damage which is incomparably better visualized by MR imaging then by CT scanning. Patients with this diagnosis have a reason to be referred first to the MRI then to the CT. Most of patients were originally referred to the lubar spine plain $\mathrm{x}$-ray, then were referred to the additional radiological imaging procedures which considering the existing algorithm go throught CT to MRI.

MR imaging provides extraordinary soft tissue visualization and it is irreplaceable procedure in detection of lumbar stenosis, so it's a method of choice in cases of spine soft tissue injuries- bone marrow, spinal cord, intervertebral damages (sequestracion, hernia), with additional possibilities of simultaneously provides views in all three planes (sagittal, coronal, transversal) and all of that without ionizing radiation exposure (Herring, 2016). It's possible by MR imaging to visually differentiate disc material parts (anulus fibrosus from nucleus pulposus), protrudion from extrudion, subligamentary from transligamentary herniation, to achieve anterior longitudinal ligament differentiation, to detect spine body metastases even earlier then by radionuclide scans.

MRI procedure disadvantages are: high price, not available as conventional radiography and CT, length of procedure, claustrofobical patients, restriction for patients with ferromagnetic implants (pacemaker, aneurysmal clips, shell grenade peaces).
CT scanning remains a method of choice for bone structure visualization, in urgent cases where we should get diagnostic information as soon as possible and in presentation of excluding referrent factors at MRI.

Justification of the original reference on CT scanning on the above diagnoses in our study was very questionable. Namely, of a total of 69 referral diagnoses at CT it was 56 (81.16\%) available and 13 (18.84\%) anavaliable (N/A) diagnoses.

Following of International Classification of Diseases it could be concluded that only 7 diagnoses (12.5\%) had justified indication for CT scanning which do not indicate soft tissue damage. For the rest of 49 (87.5\%) it was obviously to suspect of soft tissue damage which were indication for MRI performing. Exception are if there were urgent sitiations where originally CT scanning should be justified. It's about worrying percent of unjustified undertaken CT procedures, even 49 of total $56(83.93 \%)$ which greatly deviates from the world average of 30\% (Linder at al., 2016). Even if we put in relationship 49 unjustified undertaken CT procedures to the total number of undertaken procedures (considering 13 of N/A as justified), again we should get worrying percent of unjustified undertaken procedures of $71.01 \%$. Shown through monetary indications: for undertaken CT procedures during the study period to UCC Tuzla it had been spent 12,314.43 KM (69 procedures x $178.47 \mathrm{KM}$ ). According the results of study, 8,745.03 KM of that amount (49 procedures $\mathrm{x}$ 178.47 KM or $0.7101 \times 12,314.43 \mathrm{KM}$ ) had been spent unnecessarily. The same nuber of patients-49, which present $71.01 \%$ of total patients, unnecessarily recived a dose of $10 \mathrm{mSv}$ during CT scanning. In addition to 
above, there is a fact that indicates an interval from CT to the next undertaken MRI provided the most possible from the insufficiency of the necessary data for the right diagnose and appropriate therapy determination.

Analyse indicates even $9(13.04 \%)$ of patients performed additional MRI the same day or the next day from the previous undertaken CT. Until third day from the undertaken CT to MRI the number of patients increased to 19 (27.54\%), that by the eight day reached the number of 34 patients (49.28\%). Even 57 (82.61\%) of patients performed additional MRI for the duration of the acute phase of LBP (within 42 days).

Observing the patients with the most frequent referral diagnosis on CT, M51, for 36 (52.17\%) of them period passed from CT scanning to additional MR imaging were next: under 42 days $30(83.33 \%)$ of patients, all other were in group of over 85 days, them $6(16.67 \%)$. These data are very important if we are familiar with mentioned fact that by the stages of acuteness LBP is divided into three phases (acute- under 42 days, subacute-43-84 and chronic- over 85 days) and each of their treatment. Acute pain treatment, except possibly plain $x$-ray imaging, usually does not implies urgency of additional radiological imaging. The reason is that $80 \%$ of acute pain deales by analgesics therapy or additional physical therapy. About $80 \%$ of all patients with LBP that visit physican should be dealed at the level of primary health care (Linder at al., 2016; Casser, 2011).

Our study indicates next: in a group under 42 days passed from CT to MRI, which we could considered an acute phase of pain, there were a total of 57 patients (82.61\%), in a group 43-84=2 (2.90\%) and in a group over 85 days 10 patients (14.49\%) which are worrying data.

Then the question arises about such high percentage $(49.28 \%)$ of patients who, within 8 days of the undertaken CT, would be referred to an additional MRI. Within 42 days percentage rose to even $82.61 \%$. Whether referring at radiological imaging procedures (CT, MRI) was necessary at all, whether the acute phase pain could be treated in the aforementioned manner, possible by plain x-ray imaging, whether the CT scanning necessary, could CT scanning be avoided and could patient be sent directly at MRI if there was already an indication for that procedure?

The answer is not only about the decision whether is it CT scanning justified, but it is already more serious. First of all, money is spent unnecessarily, also CT tube, which number of working hours are limited, is necessarily used. There are also non-inrelevant radiation doses that patient by lumbar CT scanning recived unjustly. It's about dose of an average $10 \mathrm{mSv}$ that a patient been exposed at a pelvic area which is very radiosensitive and lumbar CT scanning is quite dangerous for children, pregnant women, person during fertile age life period, and for older patients whose bones are already affected by osteoporotic or neoplastic changes.

The research (Chou, 2009) have been established with certainty that imaging diagnosis has no greater impact on the outcome of treatment, expecially over an acute phase period, except in situations where are the strict idications to take them (trauma, fracture). Research from 2011. (Andersen, 2011) presented summary results of LBP studies undertaken during 1966.-2008. The results were very similar of Chou's results from 2009.

More recent study (Petersen, 2017) had a purpose to establish the most accurate algorithms (Clinical Diagnostic Rules, CDR) for diagnosing the most frequent patoanatomic LBP causes. The following databases are used: MEDLINE, EMBASE and CINAHL, combining results of 64 studies undertaken by at least two independent researches. The research results, as well as the recommendations, were expected- first to identify the signs and symptoms of the condition, then possibly radiological imaging undertaking by utilizing the most suitable modality for pain source visualizing (depending on whether it's about soft tissue or bone structure).

Certainly there are options for adjustening of algorithm in LBP diagnostic procedure. It is possible to find it following examples of change in the world by monitoring the justification of their results throught Evidence Based Medicine (EBM). One of the studies which dealt with the limited MRI procedure introduction and by comparision with conventional detailed MRI procedure is a study from 1996. (Robertson at al., 1996).

Rapid scans of the limited MRI protocols (T2W FSE sag and T2W FSE tra) with 2,5 minutes duration, proved to be adequate in detectioning potentional significantly degenerative conditions of the lumbar spine.

Including preparing procedure time, it is about 10-15 minutes, which excludes the usual fact about duration of MRI of more than 30 minutes (Robertson at al., 1996).

Considering the fact that radiation-induced carcinogenesis, as a direct effect of exposure to the cumulative effective equivalent dose of $100 \mathrm{mSv}$ is $2-7 \%$, depending on the studies undertaken (Brenner at al., 2007; Einstein, 2012; Berrington, 2016). It could be concluded this is a major problem that has not been sufficiently actualized. It's already stated that adult patient of average body weight has been exposed in average $10 \mathrm{mSv}$ of effective equivalent dose by lumbar CT scanning. If we are considering higher body weight patient, which is quite a case, the dose is rising rapidly. The same result we have by performing procedures on diagnostic devices that do not functioned properly or handeled by inadequately trained personnel. During LBP diagnostic performing a patient also could originally be referred to pelvis or abdomen diagnostic imaging, suspecting that pain originally comes from that region. In that case, a patient would be expose by an additional radiation dose of $12 \mathrm{mSv}$ for native and than, the most common, by an extra additional dose of $12 \mathrm{mSv}$ by postcontrast imaging.

Regardless of the above, some of the patients had been referred several times during a year at control CT scanning, absolutely ignoring the fact that radiation 
ionizing doses have been cumulated and those are life threatening (Bohl at al., 2017). For sure that could be a public health issue in the future.

A fact that would not be forgotten is that this study has been considering just those patients whom both of lubar diagnostic procedures, CT and MRI, were performed at UCC Tuzla. It remains a question of the percentage justification of all other kinds of the CT scanning. No answered remains an issue how many of patients some of the procedures, or both, had been performed outside of UCC and how many of them the CT scanning had been repeated several times. There are not any of records about such the cases.

Recording would definitely be established, as well as health institutions would be linked into a unique information system.

The best solution would be a method to record radiation for each patient individually. That could be done by electronic cards, as it is worldwide, or by electronic data base unless the health institutions are connected into a unique system. Until then, at least, manual registration would be established by each performing.

\section{CONCLUSIONS}

1. There are justified reasons for an algorithm adjustment by diagnosing of Lower Back Pain at University Clinical Center Tuzla;

\section{REFERENCES}

1. Andersen (2011) Is imediate imaging important in managing low back pain? J Athl Train 46(1): 99-102.

2. Berrington GA, Salotti JA, McHugh K, Little MP, Harbron RW, Lee C, Ntowe E, Braganza MZ, Parker L, Rajaraman P, Stiller C, Stewart DR, Craft AW, Pearce MS (2016) Relationship between paediatric $C T$ scans and subsequent risk of leukaemia and brain tumors: assesment of the impact of underlying conditions. $\mathrm{Br} J$ Cancer 114(4): 388-394.

3. Bohl DD, Hiji FY, Massel DH, Mayo BC, Long WW, Modi KD, Narain AS, Manning BT, Ahn J, Lonie PK, Singh K (2017) Patient knowledge regarding radiation exposure from spinal imaging. Spine J 17(3): 305-312.

4. Brenner JD, Hall JE, Phill D (2007) Computed Tomography- An Increasing Source of Radiation Exposure. N Engl J Med 357: 2277-2284.

5. Carey TS, Garret J (1996) Patterns of ordering diagnostic tests for patient with acute low back pain. The Nord Carolina Back Pain Project. Ann Intern Med 125(10): 807-814.

6. Casser HR, Seddigh S, Rauschmann M (2016) Acute lumbar back pain- investigation, differential diagnosis and treatment. Dtsch Artzebl Int 113(13): 223-234.

7. Chou R, Carrino JA, Deyo RA (2009) Imaging strategies for low-back pain: Systematic review and meta-analysis. Lancet 373(9662): 463-472.

8. Einstein AJ (2012) Beyond the Bombs: Cancer Risks from LowDose Medical Radiation. Lancet 380(9840):445-457.
2. It is shown the possibility to shortening of diagnostic procedure in Lower Back Pain;

3. It is pointed out the already existing study results of radiation-induced carcinogenesis as a consequence of acumulative radiation doses over 50 and over $100 \mathrm{mSv}$;

4. It is shown the possibility of financial savings due to potentional adjusting of diagnostic procedure algorithm;

5. It was noticed that there is no type of registry to note of accumulating inonizing doses which patients are exposed during performed radiological imaging.

\section{Recommendations:}

1. To adopt existing lumbar diagnostic procedures algorithm at University Clinical Center Tuzla;

2. To emphasise the possibility of unnecessary exposure to ionizing radiation during additional diagnostic procedure performing;

3. To monitor and highlight periodic potential savings from avoiding unnecessary undertaken CT procedures;

4. To take an adventage of the possibility to redirect the achieved savings due to potentional change of diagnostic algorithm procedures;

5. To suggest a method for dealing the lack to record of accumulated ionizing doses of radiation.

9. Hart LG, Deyo RA, Cherkin DC (1995) Physician office visits for low back pain. Frequency, clinical evaluation, and tretment patterns from a U.S. national survey. Spine (Phila Pa 1976)20(1): 11-19.

10. Hebrang A, Klarić-Čustović R (2007) Promjene u stanicama nakon zračenja. U: Hebrang A (14-15). Prevencija i zaštita od zračenja. U:Brnić Z (27-30). Radiološka dijagnostika mekih tkiva. U: Potočki K (259).

11. Herring W (2016) Recognizing Some Common Couses of Neck and Back Pain. Learning radiology (Recognizing The Basic). Elsevier. Philadelphia: 266-278.

12. Konin GP, Walz DM (2010) Lubosacral Transitional Vertebrae: Classification, Imaging Findings, and Clinical Relevance. Am J Neuroradiol 31(10):1778-1786.

13. Linder R, Horenkamp-Sontag D, Engel S, Schneider U, Verheyen F (2016) Quality Assurance using routine data: Overdiagnosis by radiological imaging for back pain. Dtsch Med Wochenschr 141(10): e96-e103.

14. Petersen T, Laslett M, Juhl C (2017) Clinical classifications in lover back pain: best-evidence diagnostic rules based on systematic reviews. BioMedCentral: 10.1186/s12891-017-1549-6.

15. Robertson WD, Jarvik JG, Tsuruda JS, Koepsell TD, Maravilla KR (1996) The comparasion of a rapid screening MR protocol with a conventional MR protocol for lumbal spondylosis. AJR Am J Roentgenol 166(4): 909-916.

16. Zeller JL, Burke AE, Glass RM (2006) Herniated Lumbar Disks. JAMA 296(20):2512. 